\title{
Ion Beam Implantation and Plasma Immersion Ion Implantation. Application on Nitrided Ti-6Al-4V Titanium Alloy
}

\author{
Agnès Fabre $\left({ }^{1}\right)$, Laurent Barrallier $\left({ }^{1}\right)$, Frank Torregrosa $\left({ }^{2}\right)$ \\ and Laurent Roux $\left({ }^{2}\right)$ \\ $\left({ }^{1}\right)$ Laboratoire MécaSurf, ENSAM, 2 cours des Arts et Métiers, 13617 Aix-en-Provence, France \\ $\left({ }^{2}\right)$ Ion Beam Services (IBS), 101 ZI des Pradeaux, 13850 Gréasque, France
}

(Received September 10, 1997; accepted March 16, 1998)

\author{
PACS.81.40.Pq - Friction, lubrication, and wear \\ PACS.81.15.Jj - Ion and electron beam-assisted deposition; ion plating \\ PACS.68.35.Gy - Mechanical and acoustical properties; adhesion
}

\begin{abstract}
Due to its mechanical properties and low density, the Ti-6Al-4V titanium alloy is used in hip prostheses. But the tribological behavior of Ti- $6 \mathrm{Al}-4 \mathrm{~V}$ sliding against ultra high molecular weight polyethylene involves wear degradations. The wear behavior of (Ti-6Al$4 \mathrm{~V} / \mathrm{UHMWPE}$ ) couple can be improved by ion implantation of nitrogen. After a characterization study to find the optimal parameters for classic ion implantation, this study presents an analysis of wear behavior in comparison with chemical composition, microhardness and adhesion work for a new implantation technique, plasma immersion ion implantation.
\end{abstract}

\section{Introduction}

Titanium alloy Ti-6Al-4V is used in articular prostheses like hip joint or knee joint because of its low density, high Young modulus and excellent biocompatibillity. In order to decrease wear, to reduce the adhesion coefficient and to improve the friction behavior against UHMWPE, we have studied the effect of a surface treatment: ion implantation. A first study was conducted to characterize the friction and wear behavior of Ti-6 Al- $4 \mathrm{~V}$ titanium alloy nitrogen implanted with different doses [1]. This study allowed us to validate a set of specific characterization methods for ion implanted surfaces. In the present study we have used all these protocols in order to compare two implantation techniques: the classic ion beam implantation and the plasma immersion ion implantation. Plasma immersion ion implantation or PIII is a three-dimensional implantation technique, developed for about 10 years, which allows high implantation current and is well adapted to mechanical parts treatment. The main aim of the study is to see if Ti-6Al-4V treated by classical implantation or by PIII presents the same characteristics. 


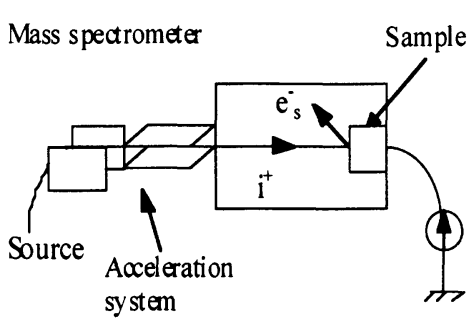

Ion beam implantation

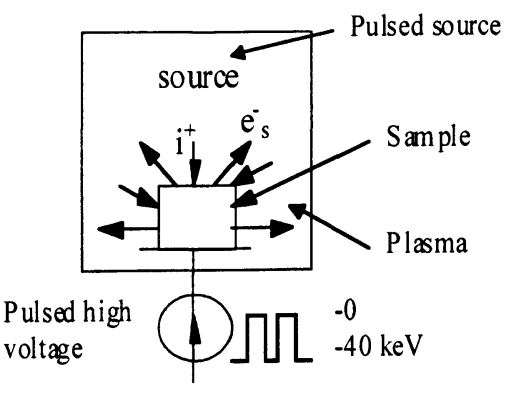

Plasma immersion ion implantation

Fig. 1. - Two different techniques of implantation.

\section{Experimental Details}

\subsection{Treatment Conditions}

Samples were cylinders made of Ti-6Al-4V, extra low interstitial grade, $25 \mathrm{~mm}$ in diameter and $15 \mathrm{~mm}$ high. They were surface polished $\left(R_{\mathrm{a}}=0.04 \mu \mathrm{m}\right.$ with $\left.\lambda_{\mathrm{c}}=0.8 \mathrm{~mm}\right)$ and treated on one side [2]. Two types of treatment were used. At first, we used classical ion beam implantation of nitrogen with an energy of $40 \mathrm{keV}$ and doses ranging from $2 \times 10^{17}$ to $5 \times 10^{17} \mathrm{~N}^{+} / \mathrm{cm}^{2}$ (on Varian DF4 device) leading to a nitrogen maximum concentration from 10 at\% to 50 at\%. In a second step, we used the new PIII technical (Plasma Immersion Ion Implantation) on a IBS (Ion Beam Services) self made machine (MECAIONIC device). On this machine, plasma and sample bias are pulsed. The sample bias voltage corresponds to a capacitor discharge, the acceleration energy during a pulse being thus not constant. In this experiment it was ranging from 10 to $30 \mathrm{keV}$. As plasma was mainly constituted of $\mathrm{N}_{2}^{+}$ions, the equivalent mean energy for $\mathrm{N}^{+}$was about $13 \mathrm{keV}$. This explains that the treated layer with PIII was thinner than the one obtained by classical ion beam implantation. Moreover, the fact that energy distribution during a pulse is a decreasing exponential curve, corresponding to a capacitor discharge, explains that concentration profiles reach their maximum very near to the surface. For PIII, because of secondary electron emission, dose was estimated using a standard sample controlled by RBS. For both treatment techniques, no external heating neither cooling was used. Differences between the two implantation devices are shown in Figure 1.

\subsection{Phase Analysis}

\subsubsection{Theoretical Phase Prediction}

For each treated sample, we have obtained the theoretical nitrogen distribution by using simulation codes as TRIM [3] or PROFIL CODE for ion beam implantation and a self made simulation code based on PRAL calculation for PIII [3,4]. We performed a thermodynamical study to predict the layer composition. This work was performed using THERMOCALC ${ }^{\circledR}$ software which determines the thermodynamical equilibrium by minimizing the total Gibbs energy [5]. The hypothesis, which consists in assuming that the system has reached equilibrium, can be considered valid for high dose implanted samples which were treated at $425^{\circ} \mathrm{C}$ during $1 \mathrm{~h}$ (average temperature during implantation due to the incident beam power). However this assumption is to be considered cautiously for low dose treated ones $\left(220^{\circ} \mathrm{C}\right.$ during $10 \mathrm{~min}$ ) and for PIII for which treatment temperature was about $150{ }^{\circ} \mathrm{C}$. 

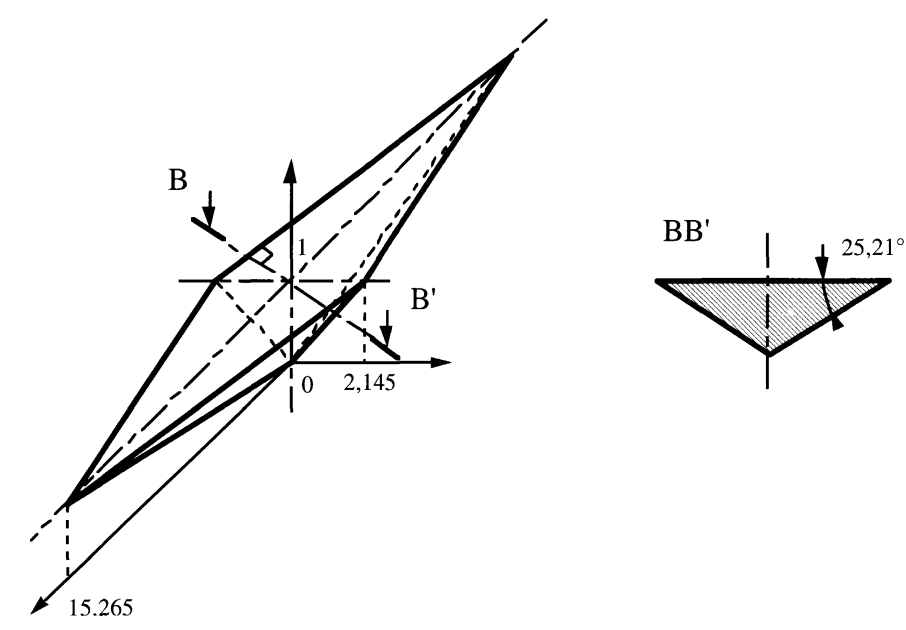

Fig. 2. - Specific geometry of the Knoop indentor.

\subsubsection{Experimental Phase Determination}

The phases predicted above were experimentally determined using grazing X-ray diffraction devices (SIEMENS D5000 and SEIFERT MZ IV goniometers) with a wavelength of $0.154 \mathrm{~nm}$ $\left(\mathrm{Cu}-\mathrm{K}_{\alpha}\right)$ and $0.229 \mathrm{~nm}\left(\mathrm{Cr}-\mathrm{K}_{\alpha}\right)$.

\subsection{Microhardness}

Since the implanted layer is very thin $(0.06-0.15 \mu \mathrm{m})$, it is impossible to estimate its hardness using an usual method. Thus, we have adapted the composite hardness model introduced by Jöhnsson and Hogmark [6] for a Knoop indentor [7]. Indeed, the specific geometry of the Knoop indentor (Fig. 2) allows lower penetration depths than those obtained by a Vickers indentor with the same normal load, thus thinner layers can be observed. This model allowed us to estimate the absolute hardness of the implanted layer knowing the substrate characteristics and the thickness of the treated layer. The principle of this method consists in considering the treated sample as a composite material that is constituted by an homogeneous substrate below an homogeneous treated layer with a known thickness. Microhardness measurements with variable loads on a non-treated sample and on an implanted one allow to calculate the characteristics of the substrate and those of the composite. From these data, intrinsic characteristics of the treated layers can be determined. In the Knoop method, which is adopted in this investigation, the hardness is defined as:

$$
H_{\mathrm{s}}=F / S=14.228(9.81 F) / L^{2}
$$

where $L$ is the major diagonal of the indentation in $\mathrm{mm}$ and $F$ the applied load in $N$. Generally, the microhardness of the substrate can be fitted to a curve of type:

$$
H_{\mathrm{s}}=H_{\mathrm{s} 0}+k_{\mathrm{s}} L^{-1}
$$

where $H_{\mathrm{s} 0}$ is considered as the absolute hardness and $k_{\mathrm{s}}$ is a constant characteristic of the material. The microhardness $H_{\mathrm{c}}$ of the composite and $H_{\mathrm{f}}$ of the treated layer follow the same type of law:

$$
\begin{aligned}
& H_{\mathrm{c}}=H_{\mathrm{c} 0}+k_{\mathrm{c}} L^{-1} \\
& H_{\mathrm{f}}=H_{\mathrm{f} 0}+k_{\mathrm{f}} L^{-1}
\end{aligned}
$$


It is possible to calculate the absolute hardness $H_{\mathrm{f} 0}$ of the treated layer if its absolute thickness $t$ is known, through the following equation:

$$
H_{\mathrm{f} 0}=H_{\mathrm{s} 0}+\frac{\left(k_{\mathrm{c}}-k_{\mathrm{s}}\right)}{2 C t}
$$

where $C$ is a constant depending on the indentation facies. In our case, $C$ is equal to 5.534 [8].

\subsection{Wear Tests}

Wear tests were performed on a reciprocal pin-on-disc machine under conditions as similar as possible to those encountered in hip joint prostheses. The frequency was fixed at one cycle per second, the lubricant was Ringer Lactate at $37{ }^{\circ} \mathrm{C}$, the test duration was one million cycles and the sliding distance equal to $92 \mathrm{~km}, 20 \mathrm{~km}$ corresponding to approximately one year's lifetime of an artificial hip joint [9]. Since the chosen counterface was gamma-irradiated (2.5 Mrad) UHMWPE (ultrahigh molecular weight polyethylene), we have estimated the contact pressure for hip prostheses with heads of $30 \mathrm{~mm}$ in diameter using a Winkler foundation model [7]. It was found to fall between $3.45 \mathrm{MPa}$ and $7.2 \mathrm{MPa}$ depending upon the clearance and the acetabular cup thickness. Four discs were subjected to wear tests a non-treated, surfacepolished one, a $2 \times 10^{17} \mathrm{~N}^{+} / \mathrm{cm}^{2}$ implanted one and a $5 \times 10^{17} \mathrm{~N}^{+} / \mathrm{cm}^{2}$ implanted one for a beam implantation and a $3.6 \times 10^{17} \mathrm{~N}^{+} / \mathrm{cm}^{2}$ implanted one for PIII. Each disc was subjected to sliding tests under $3.45 \mathrm{MPa}$ contact pressure. After one million cycles, tests were stopped and samples observed by means of optical microscopy, scanning electron microscopy (SEM) and three-dimensional tactile roughness apparatus (SOMISCAN, SURFASCAN facilities). As UHMWPE is permeable to water, and as the pin wear was of the order of a few micrometers, wear rate evaluation was difficult to estimate by means of an often-used weight measurement. Thus we have developed a specific measurement technique $[7,8]$. This method is based on the comparison of surface topography before and after wear tests.

\subsection{Adhesion Work}

The adhesion work $W_{\text {MO }}$ between UHMWPE and Ti-6Al-4V samples was determined using the Young method as shown in Figure 3, contact angles $\theta$ were measured using two liquids: water and an organic phase (heptan) simulating UHMWPE [1]. Adhesion work was calculated using the Dupré formula [10]:

$$
W_{\mathrm{MO}}=\gamma(1-\cos \theta)
$$

where $\gamma$ is the surface tension of heptan in the water.

\section{Results}

\subsection{Phase Analysis}

The theoretical nitrogen distribution profiles obtained by simulation programs are presented in Figure 4. We can see that for classical beam implantation, the maximum of nitrogen concentration is reached at a given distance below the surface. For PIII, this maximum is reached at the surface. This characteristic is due to non constant energy distribution during treatment process. Phase predictions using thermodynamical calculations are presented in Table I. For classical implantations, the treated layer composition depends upon the nitrogen dose and upon the penetration depth, treatment temperature having no significant influence. Up to $2 \times 10^{17} \mathrm{~N}^{+} / \mathrm{cm}^{2}$ the layer consists of a solid solution of nitrogen in $\alpha$-Ti, $\mathrm{Ti}_{3} \mathrm{Al}$ and 


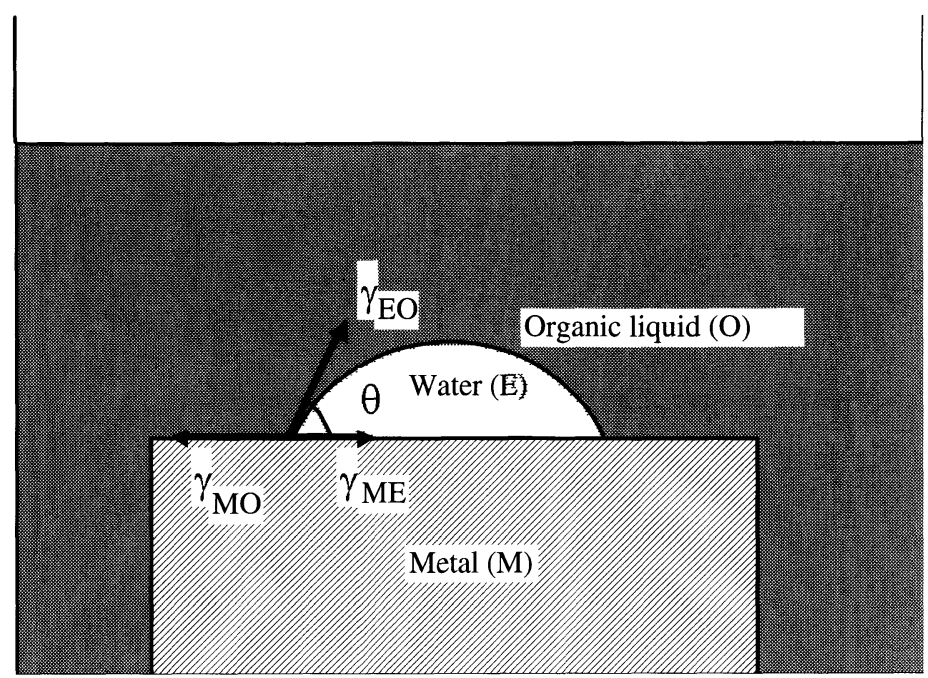

Fig. 3. - Contact angle measurement.

a)
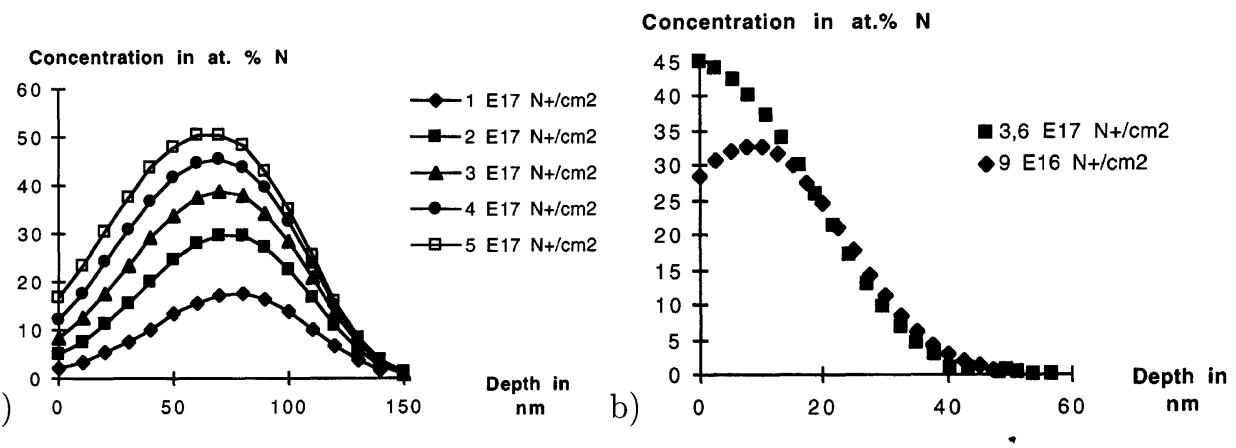

Fig. 4. - Theoretical nitrogen distribution profiles. a) Ion beam implantation. b) Plasma immersion ion implantation.

$\mathrm{Ti}_{2} \mathrm{~N}$. As the dose increases, $\alpha$-Ti disappears to form $\mathrm{Ti}_{2} \mathrm{~N}, \mathrm{Ti}_{3} \mathrm{Al}$ remains unchanged. In the range from $2 \times 10^{17} \mathrm{~N}^{+} / \mathrm{cm}^{2}$ to $5 \times 10^{17} \mathrm{~N}^{+} / \mathrm{cm}^{2}$ titanium nitride appears at a depth of around $80 \mathrm{~nm}$ at the expense of $\mathrm{Ti}_{3} \mathrm{Al}$. Above $5 \times 10^{17} \mathrm{~N}^{+} / \mathrm{cm}^{2}$ nitrogen saturation in $\mathrm{Ti}$ is reached and $\mathrm{N}_{2}$ begins to appear (gazeous bubbles may even be observed) [11].

For PIII treated samples, we mainly observed TiN between 0 and $15 \mathrm{~nm}$, then $\mathrm{Ti}_{2} \mathrm{~N}$ between 15 and $30 \mathrm{~nm}$ and finally $\alpha$-Ti becomes the dominating phase.

\subsection{Experimental Validation}

This phase prediction concerning $\mathrm{TiN}$ and $\mathrm{Ti}_{2} \mathrm{~N}$ is confirmed by grazing X-ray diffraction spectra presented in Figure 5; nevertheless, the amount of observed $\mathrm{Ti}_{2} \mathrm{~N}$ is lower than the predicted one. $\mathrm{Ti}_{3} \mathrm{Al}$ has not been observed in diffraction paterns. This can be due to the validity of the thermodynamical equilibrium hypothesis or to the fact that $\mathrm{Ti}_{3} \mathrm{Al}$ precipities are too small for diffraction observation. 

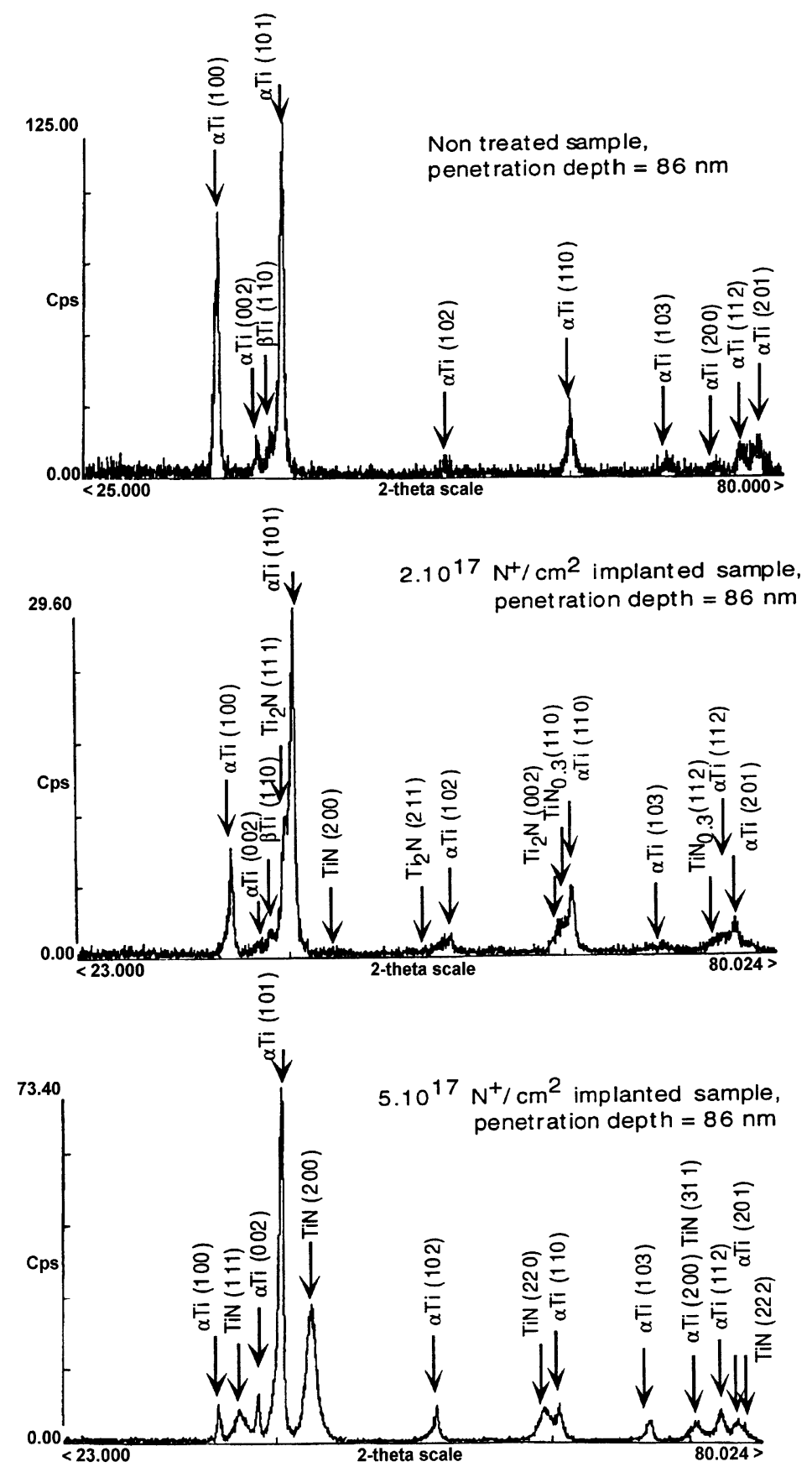

Fig. 5. - Phase analysis using grazing angle X-ray diffraction. 
Table I. — Theoretical layers constitution obtained using Thermocalc.

\begin{tabular}{|c|c|c|c|c|}
\hline $\begin{array}{l}\text { Depth } \\
\text { in } \mathrm{nm}\end{array}$ & $\begin{array}{c}\text { Non-treated } \\
\text { sample }\end{array}$ & $\begin{array}{c}\text { Ion beam } \\
\text { implantation } \\
2 \times 10^{17} \mathrm{~N}^{+} / \mathrm{cm}^{2}\end{array}$ & $\begin{array}{c}\text { Ion beam } \\
\text { implantation } \\
5 \times 10^{17} \mathrm{~N}^{+} / \mathrm{cm}^{2}\end{array}$ & $\begin{array}{c}\text { Plasma immersion ion } \\
\text { implantation } \\
3.6 \times 10^{17} \mathrm{~N}^{+} / \mathrm{cm}^{2}\end{array}$ \\
\hline 0 to 5 & \multirow{7}{*}{$\alpha-\mathrm{Ti}$} & \multirow{5}{*}{$\begin{aligned} & \alpha-\mathrm{Ti} \\
+ & \mathrm{Ti}_{2} \mathrm{~N} \\
+ & \mathrm{Ti}_{3} \mathrm{Al}\end{aligned}$} & \multirow{2}{*}{$\begin{array}{c}\alpha-\mathrm{Ti}+\mathrm{Ti}_{2} \mathrm{~N} \\
+\mathrm{Ti}_{3} \mathrm{Al}\end{array}$} & $\mathrm{TiN}$ \\
\hline 5 to 15 & & & & $\mathrm{Ti}_{2} \mathrm{~N}+\mathrm{TiN}$ \\
\hline 15 to 20 & & & $\mathrm{Ti}_{2} \mathrm{~N}+\mathrm{Ti}_{3} \mathrm{Al}$ & $\mathrm{Ti}_{2} \mathrm{~N}+\mathrm{Ti}_{3} \mathrm{Al}+\alpha-\mathrm{Ti}$ \\
\hline 20 to 30 & & & $\mathrm{Ti}_{2} \mathrm{~N}+\mathrm{TiN}$ & $\begin{array}{l}\mathrm{Ti}_{2} \mathrm{~N}+\mathrm{Ti}_{3} \mathrm{Al} \\
+\alpha-\mathrm{Ti}+\beta-\mathrm{Ti}\end{array}$ \\
\hline 30 to 45 & & & & $\mathrm{Ti}_{3} \mathrm{Al}+\alpha-\mathrm{Ti}+\beta-\mathrm{Ti}$ \\
\hline 45 to 60 & & $\mathrm{Ti}_{2} \mathrm{~N}+\mathrm{Ti}_{3} \mathrm{Al}$ & TiN & \multirow[t]{2}{*}{$\alpha-\mathrm{Ti}$} \\
\hline 60 to 100 & & $\mathrm{Ti}_{2} \mathrm{~N}+\mathrm{TiN}$ & & \\
\hline 100 to 120 & \multirow[t]{4}{*}{$\beta$-Ti } & $\mathrm{Ti}_{2} \mathrm{~N}+\mathrm{Ti}_{3} \mathrm{Al}$ & $\mathrm{TiN}+\mathrm{Ti}_{2} \mathrm{~N}$ & \multirow{4}{*}{$\beta-\mathrm{Ti}$} \\
\hline 120 to 140 & & $\begin{array}{c}\alpha-\mathrm{Ti}+\mathrm{Ti}_{2} \mathrm{~N} \\
+\mathrm{Ti}_{3} \mathrm{Al}\end{array}$ & $\begin{array}{c}\alpha-\mathrm{Ti}+\mathrm{Ti}_{2} \mathrm{~N} \\
+\mathrm{Ti}_{3} \mathrm{Al}\end{array}$ & \\
\hline 140 to 170 & & $\alpha-\mathrm{Ti}+\mathrm{Ti}_{3} \mathrm{Al}$ & $\alpha-\mathrm{Ti}+\mathrm{Ti}_{3} \mathrm{Al}$ & \\
\hline over 170 & & $\alpha-\mathrm{Ti}+\beta-\mathrm{Ti}$ & $\alpha-\mathrm{Ti}+\beta-\mathrm{Ti}$ & \\
\hline
\end{tabular}

\subsection{Microhardness}

Results are presented in Figure 6 for classical implantation, microhardness is mainly related to TiN concentration. It is about $300 \mathrm{HK}$ for a non treated sample and does not increase for the $\mathrm{Ti}_{2} \mathrm{~N}$ mainly constituted treated layer. It reaches $1200 \mathrm{HK}$ for the TiN mainly constituted treated layer. For PIII sample, the microhardness reaches $924 \mathrm{HK}$.

\subsection{Friction Coefficient}

Curves of friction coefficient $f$ versus the number of cycles are presented in Figure 7 . It seems that the nitrogen dose does not significantly modify the friction coefficient. Indeed after run-in stage, $f$ stabilizes around 0.03 , brutal increases being observed when scratch appears. For PIII treated sample, the friction coefficient was around 0.06, as we can see in Figure 8.

\subsection{Wear of UHMWPE Pins}

For all the tests, UHMWPE wear is adhesive and abrasive. Wear factors of the pins are presented in Table II. PIII nitrogen implantation, as well as classical beam treatment have decreased the wear of UHMWPE. We can note that for classical ion implantation the minimum of wear is obtained for the $\mathrm{Ti}_{2} \mathrm{~N}$ mainly constituted sample $\left(2 \times 10^{17} \mathrm{~N}^{+} / \mathrm{cm}^{2}\right)$. 


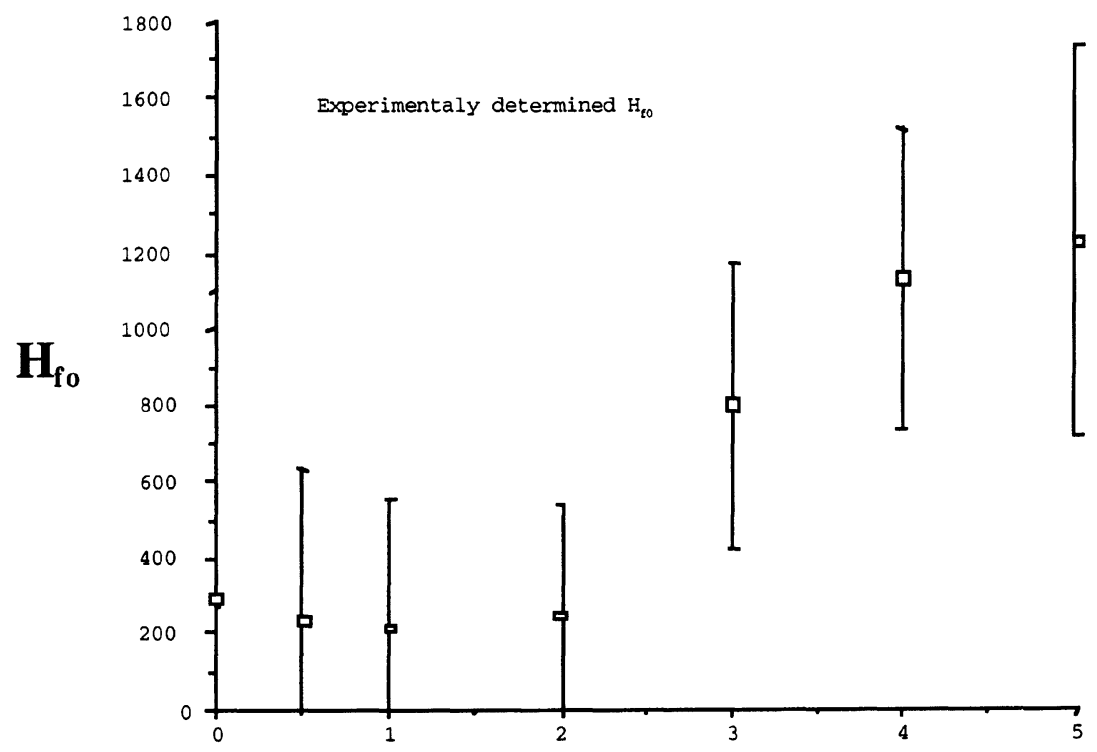

Dose $\left(10^{17} \mathrm{~N}^{+} / \mathrm{cm}^{2}\right)$

Fig. 6. - Absolute hardness of the treated layer vs. nitrogen implanted dose.

\section{Contact pressure $=3,45 \mathrm{MPa}$}

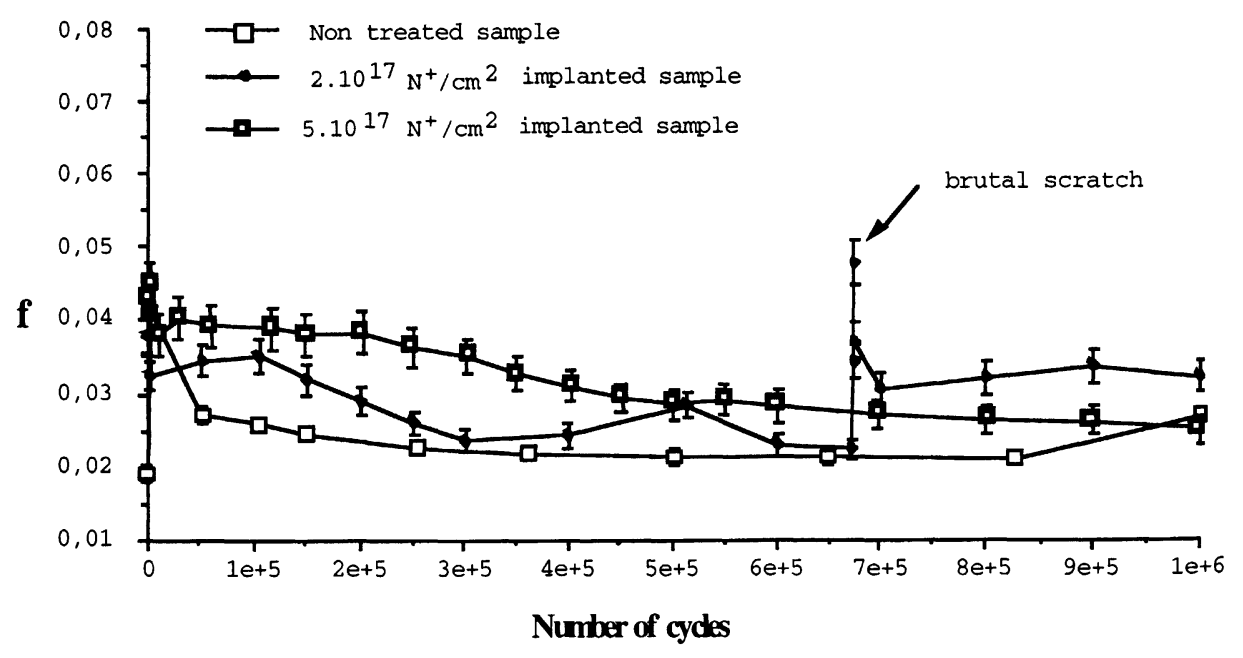

Fig. 7. - Friction coefficient vs. number of cycles, for non treated and ion beam implanted samples. 


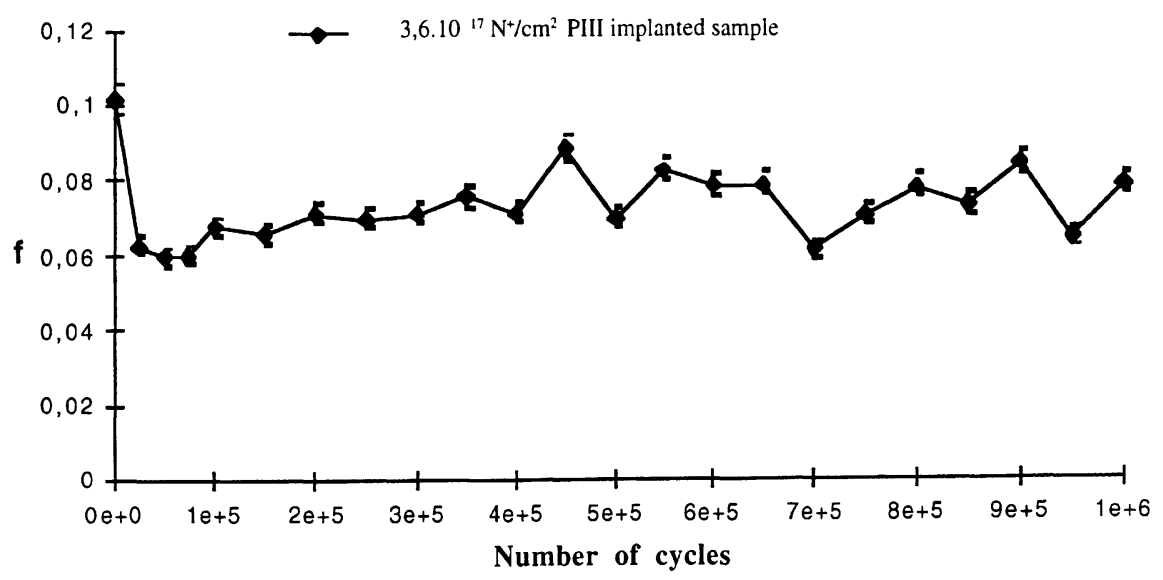

Fig. 8. - Friction coefficient vs. number of cycles, for PIII implanted sample.

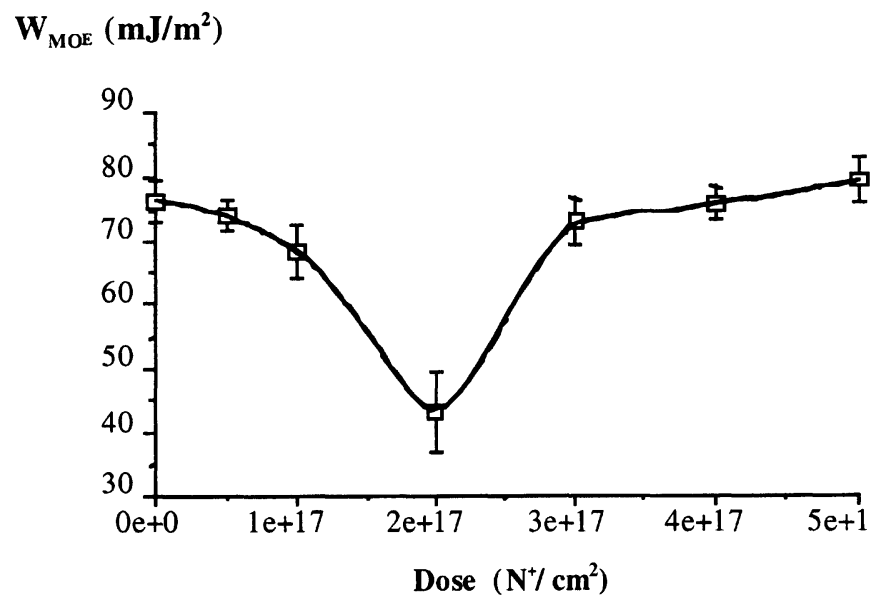

Fig. 9. - Adhesion work variation between implanted Ti-6Al-4V and heptan.

\subsection{Adhesion Work between Implanted Ti-6Al-4V and UHMWPE}

Adhesion work measurements are presented in Figure 9. For classical implantation a minimum is obtained with the $2 \times 10^{17} \mathrm{~N}^{+} / \mathrm{cm}^{2}$ dose. For PIII, no modification indication of adhesion work has been established. As shown in a previous article [7], this minimum of adhesion could be attributed to the main presence of $\mathrm{Ti}_{2} \mathrm{~N}$ that is likely of oxidize forming $\mathrm{TiO}$, though non treated and TiN containing samples are likely to form $\mathrm{TiO}_{2}$.

Table II. - Wear of UHMWPE pins.

\begin{tabular}{|c|c|c|c|c|}
\hline Treatment & $\begin{array}{c}\text { Non-treated } \\
\text { sample }\end{array}$ & $\begin{array}{c}\text { Classical } \\
\text { implantation: } \\
2 \times 10^{17} \mathrm{~N}^{+} / \mathrm{cm}^{2}\end{array}$ & $\begin{array}{c}\text { Classical } \\
\text { implantation: } \\
5 \times 10^{17} \mathrm{~N}^{+} / \mathrm{cm}^{2}\end{array}$ & $\begin{array}{c}\text { PIII: } \\
3.6 \times 10^{17} \mathrm{~N}^{+} / \mathrm{cm}^{2}\end{array}$ \\
\hline Wear pin height & $16 \pm 4$ & $7 \pm 1$ & $10 \pm 3$ & $12 \pm 7$ \\
\hline
\end{tabular}




\section{Conclusion}

Our goals were to study the effects of nitrogen implantation on $\mathrm{Ti}-6 \mathrm{Al}-4 \mathrm{~V}$ in the aim of improving its tribological characteristics against UHMWPE, and to compare the classical beam implantation process to the more recent plasma immersion ion technique.

For classical beam implantation, the existence of an optimal dose was demonstrated. It corresponds with a layer mostly constitued of $\mathrm{Ti}_{2} \mathrm{~N}$. For this dose, no spectacular increase of hardness is observed but adhesion is reduced.

For PIII technique, observed phenomena seem to be comparable, even if the implantation profile and the thickness of the treated layer are not similar. Nevertheless, only one sample was tested and a complementary study must be carried on to find the optimal dose.

\section{References}

[1] Torregrosa F., Fabre A., Barrallier L. and Traskine V., Implantation ionique d'azote en milieu chloré. Application en orthopédie, Journées Internationales Francophones, STF 1996, Tribologie en environnement lubrifié et non standard, 21 au 23 mai, 1996.

[2] Norme NFS90-438-1 : Principes directeurs pour le nettoyage, le conditionnement et la stérilisation des implants orthopédiques, AFNOR, 1992.

[3] Goktepe O.F., Mater. Sci. Eng. 69 (1985) 13-20.

[4] Soufflet F., Étude et analyse d'une machine d'implantation ionique par immersion plasma, projet de fin d'études de l'École Nationale Supérieure de Physique de Marseille (19961997).

[5] Sundman B., Jonsson B. and Andersson J.O., Calphad 9 (1985) 153-190.

[6] Jöhnsson B. and Hogmark S., Thin Solid Films 114 (1984) 257-269.

[7] Torregrosa F., Prothèse totale de hanche et usure, influence de la géométrie et des matériaux, étude de l'implantation ionique d'azote sur l'alliage TA6V4. Thèse de l'Université Paris XII, Spécialité Milieux denses et matériaux (1995).

[8] Torregrosa F., Barrallier L. and Roux L., Thin Solid Films 266 (1995) 245-253.

[9] Fisher J., Dowson D., Hamdzah H. and Lee H.L., Wear 175 (1994) 219-225.

[10] Haidara H., Étude des énergies de surfaces : influence sur l'adhésion, Revue Scientifique et Technique de la Défense, deuxième trimestre 1991, pp. 131-134.

[11] Rabbe L.M., Comportement physico-chimique d'un contact métal/polymère soumis à un frottement sous petits débattements en milieu chlorure. Influence des traitements de surface par implantation et nitruration ioniques, Thèse de l'INPG et de l'École Nationale Supérieure des Mines de Saint-Etienne, N$^{\circ}$ ordre 99TD (1993). 